\title{
Suboptimal persistence with inhaled corticosteroid monotherapy among children with persistent asthma in the UK
}

\author{
Qiaoyi Zhanga, *Stephanie D Taylora, Vasilisa Sazonovª, Mike Thomas ${ }^{b}$, David Price \\ a Global Health Outcomes, Merck \& Co., Inc., Whitehouse Station, NJ, USA \\ ${ }^{\mathrm{b}}$ Centre of Academic Primary Care, University of Aberdeen, Aberdeen, Scotland, UK
}

Originally submitted 5th March 2010; resubmitted 1st July 2010; revised version received 30th July 2010; accepted 1st August 2010; online 7th October 2010

\begin{abstract}
Background: Long-term studies indicate that adherence to asthma controller therapy decreases over time, and persistence with therapy may be poor.

Methods: This primary care database study assessed persistence with therapy over one year after first prescription of inhaled corticosteroid (ICS) for children aged 2-14 years with a diagnosis of asthma. Children with intermittent asthma were excluded. Discontinuation was defined as no ICS prescription during the last three months of the follow-up year.

Results: 2220 of 7375 children receiving a first prescription for ICS had persistent asthma. Mean ( \pm SD) age was $7.3( \pm 3.8)$ years; $59.5 \%$ were male. A total of 745 (33.6\%) continued initial ICS, $133(6.0 \%)$ received add-on therapy, 150 (6.8\%) switched to another asthma therapy, and $1192(53.7 \%)$ discontinued therapy. These percentages were similar for children aged 2-5 or 6-14 years.

Conclusion: Persistence with first-time ICS monotherapy is poor among children with persistent asthma.

(C) 2011 Primary Care Respiratory Society UK. All rights reserved.

Q Zhang et al. Prim Care Respir J 2011; 20(1): 97-101

doi:10.4104/pcrj.2010.00061
\end{abstract}

Keywords asthma, inhaled corticosteroid, paediatrics, observational, persistence, therapy

\section{Introduction}

Asthma management guidelines recommend regular use of an anti-inflammatory controller (preventer) medication when symptoms are not controlled by intermittent use of short-acting $\beta_{2}$-agonist (step 2 of the guidelines). ${ }^{-3}$ For children aged $5-12$ years, current British Thoracic Society (BTS) asthma guidelines recommend an inhaled corticosteroid (ICS) as the first controller medication and, for children younger than 5 years, an ICS or leukotriene receptor antagonist. ${ }^{1}$

Regular long-term use of ICS has been shown to prevent hospitalisations for asthma, ${ }^{4}$ while suboptimal adherence to ICS has been linked to poor asthma control. ${ }^{5-8}$ Nonetheless, suboptimal adherence to prescribed controller therapy is common among both adults and children.-14 Long-term studies indicate that adherence to asthma controller therapy decreases over time, ${ }^{15,16}$ and persistence with therapy may be poor. ${ }^{17,18}$ 'Adherence' to asthma controller therapy can be defined as the proportion of doses taken as prescribed, while 'persistence' with therapy applies to duration of therapy, namely, the continued use of the prescribed medication over time. ${ }^{18,19}$

The objective of this observational study was to assess persistence with therapy after a first prescription for ICS monotherapy among children with persistent asthma, as recorded in a large primary care database.

\section{Methods}

\section{Study design and patients}

Data for this retrospective observational study were drawn from the UK MediPlus database, now known as the IMS Disease Analyzer $\mathrm{UK}^{20}$ and described in detail elsewhere. ${ }^{21}$ At the time of our study (November 2000 to October 2005), UK MediPlus contained information on approximately 2 million patient visits to a nationally representative sample of approximately 500 general practitioners (GPS) in the UK. Recorded information includes the reason for consultation, diagnosis, prescribed treatment, and secondary medical care, linked to encrypted patient identifiers.

We studied children aged 2-14 years with a diagnosis of asthma (international classification of diseases [ICD]-10

\footnotetext{
* Corresponding author: Dr Stephanie Taylor, Merck \& Co., Inc., Whitehouse Station, New Jersey, United States

Tel: +1 9084233512 Fax: +1 9087351688 E-mail: stephanie_taylor@merck.com
} 


\begin{tabular}{|c|c|c|}
\hline $\begin{array}{l}\text { Inhaled short-acting } \\
\beta_{2} \text {-agonist }\end{array}$ & $\begin{array}{l}\text { Oral } \\
\text { corticosteroid }\end{array}$ & $\begin{array}{l}\text { Asthma severity } \\
\text { classification }\end{array}$ \\
\hline$\leq 1$ prescription and & $\begin{array}{l}0 \text { prescription } \\
1 \text { prescription } \\
2 \text { prescriptions } \\
\geq 3 \text { prescriptions }\end{array}$ & $\begin{array}{l}\text { Mild intermittent* } \\
\text { Mild intermittent* } \\
\text { Moderate persistent } \\
\text { Severe persistent }\end{array}$ \\
\hline 2-3 prescriptions and & $\begin{array}{l}0-1 \text { prescriptions } \\
2 \text { prescriptions } \\
\geq 3 \text { prescriptions }\end{array}$ & $\begin{array}{l}\text { Mild persistent } \\
\text { Moderate persistent } \\
\text { Severe persistent }\end{array}$ \\
\hline 4-6 prescriptions and & $\begin{array}{c}0 \text { prescription } \\
1-2 \text { prescriptions } \\
\geq 3 \text { prescriptions }\end{array}$ & $\begin{array}{l}\text { Mild persistent } \\
\text { Moderate persistent } \\
\text { Severe persistent }\end{array}$ \\
\hline$>6$ prescriptions and & $\begin{array}{l}0-1 \text { prescriptions } \\
\geq 2 \text { prescriptions }\end{array}$ & $\begin{array}{l}\text { Moderate persistent } \\
\text { Severe persistent }\end{array}$ \\
\hline
\end{tabular}

diagnostic codes J45 [asthma] and J46 [status asthmaticus]) who initiated ICS monotherapy (step 2 of the BTS guidelines) from November 2001 to October 2004. To be eligible for the study, children had to have data available for 12 months before and 12 months after the date of the ICS prescription (index date) and no prescription for controller therapy within six months before the index date. Asthma severity was estimated using the prescription history for short-acting $\beta_{2}$-agonist and oral corticosteroid during the baseline year, as described by Leidy et al.22 (see Table 1). Children with intermittent asthma (step 1 of the BTS guidelines) were excluded from the study.

We examined the distribution of ICS monotherapy with respect to choice of drug and the mean number of ICS prescriptions written per patient over the follow-up year (prescriptions could have been for more than one inhaler). Treatment patterns were classified into four categories:

- continuation of initially prescribed ICS without change

- add-on (added long-acting $\beta_{2}$-agonist [LABA] or montelukast to ICS)

- switch (changed to another ICS, LABA, ICS-LABA combination, or montelukast)

- discontinuation (no ICS prescription during the last 3 months of the follow-up period).

Descriptive statistics were used to summarise study results. Ethics committee approval was not required for this study as the Mediplus data are anonymised.

\section{Results}

From a total of 7375 children receiving an initial prescription for ICS, we identified 2220 children with persistent asthma. The
Table 2. Demographic characteristics, asthma severity, and persistence with therapy of 2220 children who received inhaled corticosteroid monotherapy, by age category.

\begin{tabular}{lcc} 
& $\begin{array}{c}\text { Age 2-5 years } \\
(\mathrm{n}=899)\end{array}$ & $\begin{array}{c}\text { Age 6-14 years } \\
(\mathrm{n}=1321)\end{array}$ \\
\hline Age, mean (SD) & $3.5(1.1)$ & $10.0(2.5)$ \\
\hline Male sex, $\mathrm{n}(\%)$ & $546(60.7)$ & $775(58.7)$ \\
\hline Asthma severity, $\mathrm{n}(\%)$ & & \\
Mild & $752(83.7)$ & $1157(87.6)$ \\
Moderate & $115(12.8)$ & $147(11.1)$ \\
Severe & $32(3.6)$ & $17(1.3)$ \\
\hline $\begin{array}{l}\text { Persistence with ICS, n (\%) } \\
\text { Continuation }\end{array}$ & $331(36.8)$ & $414(31.3)$ \\
Add-on therapy & $41(4.6)$ & $92(7.0)$ \\
Switched asthma therapy & $48(5.3)$ & $102(7.7)$ \\
Discontinuation & $479(53.3)$ & $713(54.0)$ \\
& &
\end{tabular}

mean $( \pm$ SD) age overall was $7.3( \pm 3.8)$ years, and 1321/2220 $(59.5 \%)$ patients were male (Table 2$)$. The majority of children (1909/2220, 86.0\%) had mild persistent asthma; 262 (11.8\%) had moderate and 49 (2.2\%) severe persistent asthma.

2) Three-quarters (1740 or $78.4 \%$ ) of the initial ICS prescriptions were for beclometasone, $261(11.8 \%)$ were for fluticasone, and 219 (9.9\%) for budesonide. The mean number of ICS prescriptions recorded during the follow-up year was 3.1 (SD 2.2; range, $1-17)$. Half of children had one $(25 \%)$ or two (24\%) total ICS prescriptions; $18 \%$ received three; $14 \%$, four; $7 \%$, five; and $12 \%$, six or more prescriptions. While the record of number of treatment days supplied by each prescription was incomplete in the database, the average supply for each prescription, when recorded, was most commonly 30 days.

Overall, 745 (33.6\%) children continued their initial ICS therapy, 133 (6.0\%) received add-on therapy, 150 (6.8\%) switched to another asthma therapy, and 1192 (53.7\%) discontinued therapy. These percentages were similar in the two age-group categories of 2-5 years and 6-14 years (Table 2). Figure 1 depicts persistence with therapy according to asthma severity and Figure 2 the persistence with therapy according to ICS drug type.

\section{Discussion}

Persistence with ICS was poor, as captured in this retrospective database study, among children with persistent asthma initiating ICS monotherapy from November 2001 to October 2004. Over half $(54 \%)$ of children in the study discontinued asthma controller therapy according to our a priori definition. Moreover, during the year, two-thirds (67\%) of children received three or fewer ICS prescriptions, representing a 3- to 6-month supply at most, depending on prescription type. 
Figure 1. Persistence with inhaled corticosteroid monotherapy after a first prescription, by level of asthma severity, for 2220 children with persistent asthma. "Continuation" was defined as initially prescribed ICS without change; "add-on," as added long-acting $\beta_{2}$-agonist (LABA) or montelukast to ICS; "switch," as change to another ICS, LABA, ICS-LABA combination, or montelukast; and "discontinuation," as no ICS prescription during the last 3 months of the follow-up year.

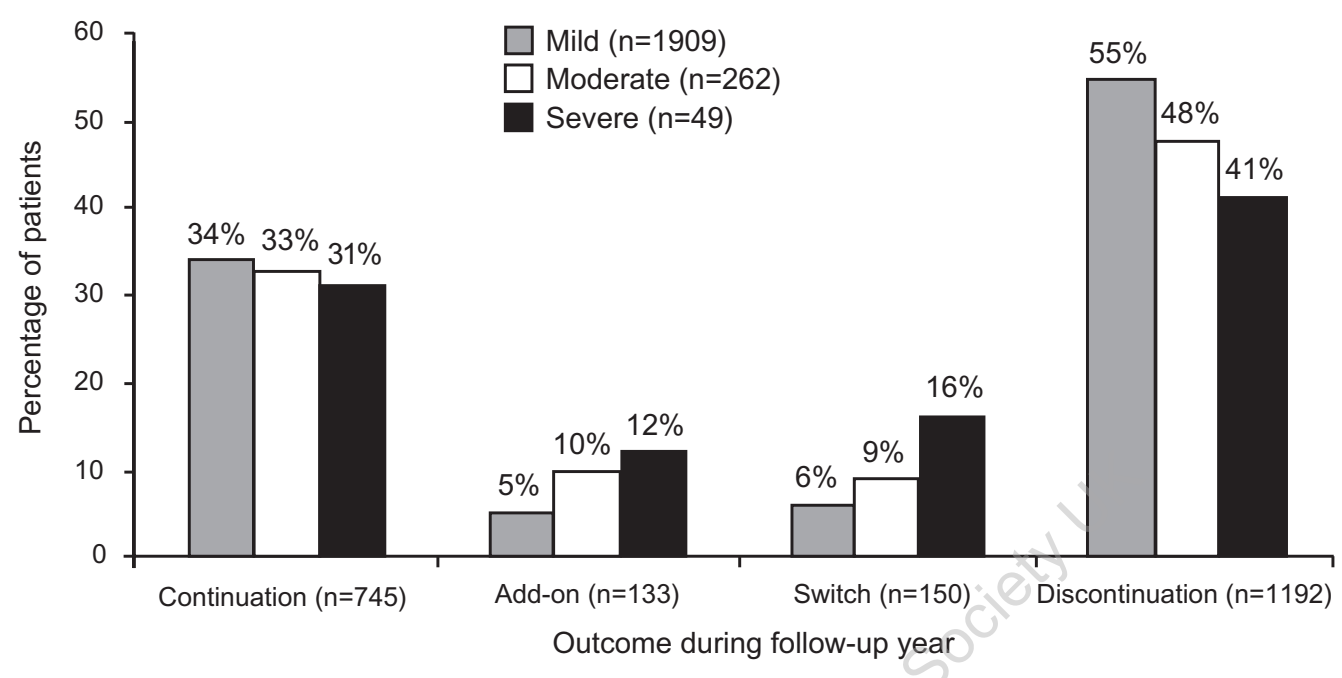

Figure 2. Persistence with each of the three drugs prescribed as first inhaled corticosteroid monotherapy for 2220 children with persistent asthma. "Continuation" was defined as initially prescribed ICS without change; "add-on," as added longacting $\beta_{2}$-agonist (LABA) or montelukast to ICS; "switch," as change to another ICS, LABA, ICS-LABA combination, or montelukast; and "discontinuation," as no ICS prescription during the last 3 months of the follow-up year.

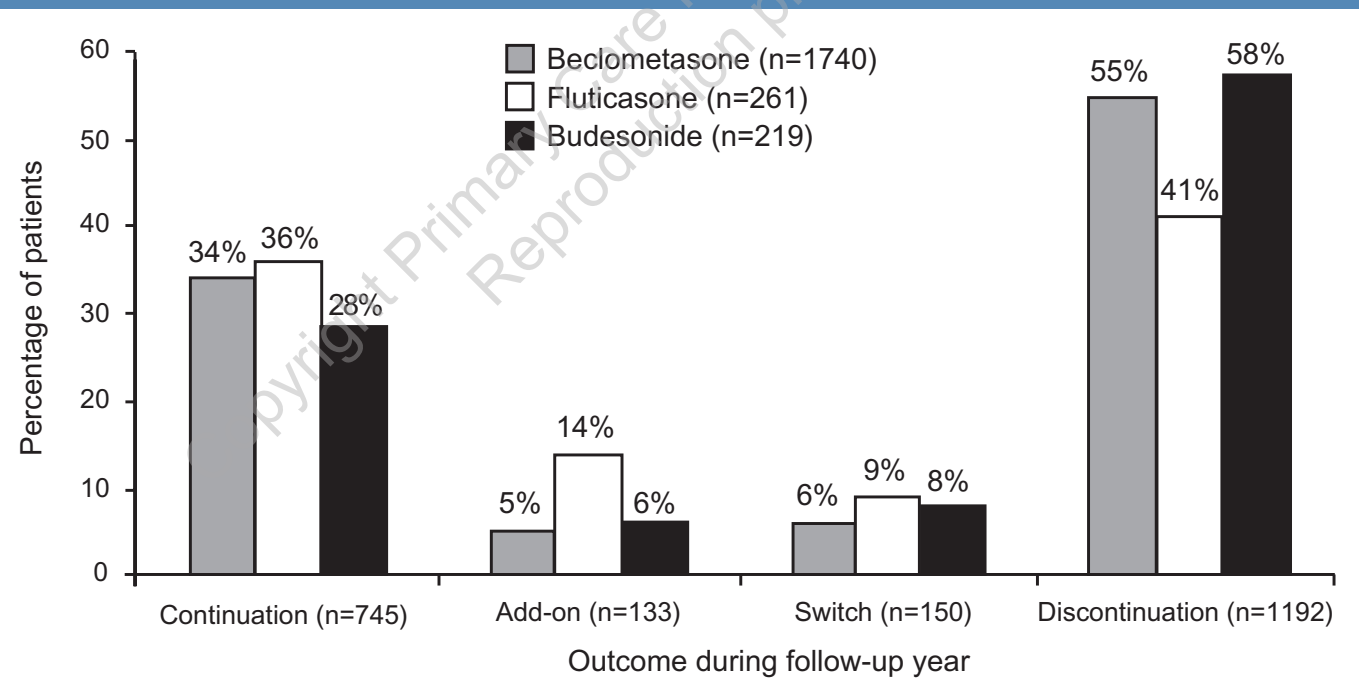

Other authors report suboptimal persistence with asthma controller therapy for first-time users of ICS. In the Netherlands, a large database study found $49 \%$ persistence at 100 days and $<10 \%$ persistence at one year after start of ICS monotherapy among patients aged 35 years and younger; the results were similar when stratified by age. ${ }^{17}$ Jones and co-workers ${ }^{19}$ reported $25 \%$ and $22 \%$ persistence with ICS monotherapy at six and nine months, respectively, in their study of pharmacy claims data in the US. In another study in the Netherlands, children were more likely to continue with their asthma medications if they received their first prescription for asthma medication at age 2 or 3 years (versus $\leq 1$ year) or if they received prescriptions for $\beta_{2}$-agonist and ICS (versus just $\beta_{2}$-agonist). ${ }^{23}$

Our findings of poor persistence with ICS were consistent for the two age groupings of 2-5 years and 6-14 years, as well as among asthma severity and ICS drug type categories. A limitation of this observational study is that the diagnosis of asthma was based on coding in the database; moreover, the 
asthma severity determinations were based on prescribing information for the baseline year, as severity was not specifically coded. We cannot rule out the possibility that some children who were classified as having persistent asthma had intermittent asthma instead. The fact that all children had a database diagnostic code for asthma suggests that a therapeutic trial although possible was unlikely. If the ICS had been prescribed before the diagnosis then a therapeutic trial would be likely, but after diagnosis it implies commencement of regular preventive therapy. Also supporting the persistent asthma classification is the fact that the children included in this study represented just $30 \%(2220 / 7375)$ of the children receiving a first prescription for ICS during the study period. Moreover, the data were consistent for older children with less diagnostic doubt. Finally, the patients in the moderate and severe asthma categories, who are the least likely to have been misclassified as having persistent asthma, had discontinuation rates of $48 \%$ and $41 \%$, respectively, not much lower than the percentage of those with mild persistent asthma who discontinued (55\%).

The severity classifications were based on the algorithm of Leidy et al.,22 which was assessed statistically in a healthcare claims database by examining the relationship between severity level and clinical variables, including deaths, hospitalisations, emergency room visits, and care from an allergist or pulmonologist. To our knowledge the algorithm has not been validated clinically or published as a full paper. Birnbaum and coworkers ${ }^{24}$ report that the Leidy algorithm, in conjunction with an asthma guideline-based classification using ICS daily dose information and derived from an administrative claims database, generally categorised patients as having more severe asthma than an approach using pulmonary function testing. Therefore, it is possible that use of the Leidy algorithm led to an overestimation of asthma severity in this study. Patients prescribed fluticasone were numerically more likely to receive add-on therapy and less likely to discontinue ICS therapy during the year, which could indicate that fluticasone was prescribed for patients considered to have more troublesome symptoms.

Our findings are dependent on the accuracy of recorded data. By studying prescriptions over a full 12 months after the index date we hoped to minimise the effect of seasonal variations in asthma symptoms and prescribing. We defined discontinuation of therapy as no prescription during the last three months of the outcome year. Because it is possible that patients were using ICS intermittently and their supply of prescribed ICS lasted longer than we estimated, it would have been ideal to follow patients for a longer period to assess persistence. Moreover, it would have been of interest to examine asthma-related outcomes in conjunction with prescribing patterns. It is also possible that patients discontinued therapy because of lack of adequate benefit for reasons that could include poor inhaler technique.
We cannot ascertain whether children did not persist with therapy because it was found that they did not actually have asthma or that they had intermittent asthma and did not need ICS. Thus, because of this diagnostic uncertainty, we cannot rule out the possibility that, rather than lacking persistence with therapy, children were initially over-treated.

In conclusion, our findings suggest that persistence with firsttime ICS monotherapy is poor among children with persistent asthma. Lack of persistence with ICS could lead to suboptimal asthma control. These data suggest that persistence with controller therapy should be routinely evaluated for children with asthma, and further study is needed to identify means of improving persistence with therapy for those children who require regular controller therapy.

\section{Conflict of interest declaration}

Qiaoyi Zhang, Stephanie D Taylor, and Vasilisa Sazonov-Kocevar are employees of Merck \& Co., Inc.

Neither Mike Thomas nor any member of his close family has any shares in pharmaceutical companies. In the last three years he has received fees for acting as a consultant for MSD, Schering, and GSK and has received speaker's honoraria for speaking at sponsored meetings from the following companies marketing respiratory and allergy products: AstraZeneca, Boehringer Inglehiem, GSK, MSD, Schering-Plough, Teva. He has received honoraria for attending advisory panels with Altana, AstraZeneca, BI, GSK, MSD, Merck Respiratory, Schering-Plough, Teva. He has received sponsorship to attend international scientific meetings from GSK, MSD, AstraZeneca. He has received funding for research projects from GSK, MSD, AstraZeneca. He holds a research fellowship from Asthma UK. He is an Associate Editor of the $P C R J$, but was not involved in the editorial review of, nor the decision to publish, this article.

David Price has consultant arrangements with Aerocrine, BI, Dey Pharmaceuticals, GSK, MSD, Novartis, Schering-Plough, and Teva. He or his team have received grants and research support for research in respiratory disease from the following organisations: UK National Health Service, Aerocrine, AstraZeneca, BI, GSK, MSD, Novartis, Pfizer, Schering Plough, and Teva. He has spoken for: BI, GSK, MSD, Pfizer, and Teva.

\section{Acknowledgements}

Writing assistance was provided by Elizabeth $\mathrm{V}$. Hillyer with financial support from Merck \& Co., Inc.

\section{References}

1 British Thoracic Society, Scottish Intercollegiate Guidelines Network. British Guideline on the Management of Asthma, May 2008, revised June 2009 (http://www.sign.ac.uk/guidelines/fulltext/101/index.html)

2 Global Initiative for Asthma (GINA). Global Strategy for Asthma Management and Prevention, updated 2009. (http://www.ginasthma.org)

3 van der Molen T, Ostrem A, Stallberg B, Ostergaard MS, Singh RB. International Primary Care Respiratory Group (IPCRG) Guidelines: management of asthma. Prim Care Resp J 2006;15(1):35-47. http://dx.doi.org/10.1016/ j.pcrj.2005.11.001

4 Suissa S, Ernst P, Kezouh A. Regular use of inhaled corticosteroids and the long term prevention of hospitalisation for asthma. Thorax 2002;57(10):880-4.

5 Lasmar L, Camargos P, Champs NS, et al. Adherence rate to inhaled corticosteroids and their impact on asthma control. Allergy 2009;64(5):784-9. http://dx.doi.org/10.1111/j.1398-9995.2008.01877.x

6 Bender B, Zhang L. Negative affect, medication adherence, and asthma control in children. J Allergy Clin Immunol 2008;122(3):490-5. http://dx.doi.org/ 10.1016/j.jaci.2008.05.041

7 Milgrom H, Bender B, Ackerson L, Bowry P, Smith B, Rand C. Noncompliance and treatment failure in children with asthma. J Allergy Clin Immunol 1996;98(6 Pt 1):1051-7. http://dx.doi.org/10.1016/S0091-6749(96)80190-4 
8 Williams LK, Pladevall M, Xi H, et al. Relationship between adherence to inhaled corticosteroids and poor outcomes among adults with asthma. J Allergy Clin Immunol 2004;114(6):1288-93. http://dx.doi.org/10.1016/j.jaci.2004.09.028

9 Lasmar L, Camargos P, Bousquet J, Goulart E, Sakurai E, Carvalhais M. Factors related to lower adherence rates to inhaled corticosteroids in children and adolescents: a prospective randomized cohort study. J Trop Pediatr 2009;55(1):20-5. http://dx.doi.org/10.1093/tropej/fmn067

10 Hasford J, Uricher J, Tauscher M, Bramlage P, Virchow JC. Persistence with asthma treatment is low in Germany especially for controller medication - a population based study of 483051 patients. Allergy 2010;65(3):347-54. http://dx.doi.org/10.1111/j.1398-9995.2009.02161.x

11 Butz AM, Tsoukleris M, Donithan M, et al. Patterns of inhaled antiinflammatory medication use in young underserved children with asthma. Pediatrics 2006;118(6):2504-13. http://dx.doi.org/10.1542/peds.2006-1630

12 Mudd K, Bollinger ME, Hsu VD, Donithan M, Butz A. Pharmacy fill patterns in young urban children with persistent asthma. J Asthma 2006;43(8):597-600. http://dx.doi.org/10.1080/02770900600878537

13 Rabe KF, Vermeire PA, Soriano JB, Maier WC. Clinical management of asthma in 1999: the Asthma Insights and Reality in Europe (AIRE) study. Eur Respir J 2000; 16(5):802-07.

14 Cochrane MG, Bala MV, Downs KE, Mauskopf J, Ben-Joseph RH. Inhaled corticosteroids for asthma therapy: patient compliance, devices, and inhalation technique. Chest 2000;117(2):542-50.

15 Jonasson G, Carlsen KH, Mowinckel P. Asthma drug adherence in a long term clinical trial. Arch Dis Child 2000;83(4):330-3.

16 Jentzsch NS, Camargos PA, Colosimo EA, Bousquet J. Monitoring adherence to beclomethasone in asthmatic children and adolescents through four different methods. Allergy 2009;64(10):1458-62. http://dx.doi.org/10.1111/j.13989995.2009.02037.x

17 Breekveldt-Postma NS, Koerselman J, Erkens JA, van der Molen T, Lammers JW, Herings RM. Treatment with inhaled corticosteroids in asthma is too often discontinued. Pharmacoepidemiol Drug Saf 2008;17(4):411-22. http://dx.doi.org/10.1002/pds.1552

18 Marceau C, Lemiere C, Berbiche D, Perreault S, Blais L. Persistence, adherence, and effectiveness of combination therapy among adult patients with asthma. $J$ Allergy Clin Immunol 2006;118(3):574-81. http://dx.doi.org/10.1016/ j.jaci.2006.06.034

19 Jones C, Santanello NC, Boccuzzi SJ, Wogen J, Strub P, Nelsen LM. Adherence to prescribed treatment for asthma: evidence from pharmacy benefits data. J Asthma 2003;40(1):93-101.

20 IMS Disease Analyzer. ((http://www.imshealth.com/portal/site/imshealth? CURRENT_LOCALE=en_gb)

21 Wong IC, Murray ML. The potential of UK clinical databases in enhancing paediatric medication research. Br J Clin Pharmacol 2005;59(6):750-5. http://dx.doi.org/10.1111/j.1365-2125.2005.02450.x

22 Leidy NK, Paramore LC, Watrous M, Doyle J, Zeiger RS. Development of an algorithm for estimating asthma severity from an administrative cost database. Value Health 1999;2:394. Abstract.

23. Schokker S, Groenhof F, van der Veen WJ, van der Molen T. Prescribing of asthma medication in primary care for children aged under 10. Prim Care Resp J 2010;19(1):28-34. http://dx.doi.org/10.4104/pcrj.2009.00039

24. Birnbaum HG, Ivanova Jl, Yu AP, et al. Asthma severity categorization using a claims-based algorithm or pulmonary function testing. J Asthma 2009;46(1):67-72. http://dx.doi.org/10.1080/02770900802503099

\section{Available online at http://www.thepcrj.org}

